\title{
Workplace Bullying, Emotions, and Outcomes
}

This study examines emotional experiences as potential mediators between exposure to workplace bullying and job satisfaction, organizational commitment, and intention to leave the organization, respectively. A total of 5,520 respondents participated in the study. Drawing upon affective events theory (AET), the results show that emotions partly mediate these relationships and, hence, support the notion that emotions play a central part in the relationship between bullying and essential occupational outcomes.

Keywords: bullying; emotions; affective events theory; job satisfaction; organizational commitment; intention to leave the organization Bullying at work has been recognized as a serious problem in contemporary working life and has been defined as harassing, offending or socially excluding someone, or negatively affecting someone's work tasks. Although the negative and unwanted nature of the behavior involved is essential to the concept of bullying, the core characteristic of bullying is not necessarily the type of the behaviors involved per se but rather the pattern and persistency of these experiences (Einarsen \& Hoel, 2008). For example, being ignored by a manager or colleagues at work may happen to anyone, but if repeated over a long period of time, such relatively harmless behaviors may be experienced as acts of bullying. Thus, bullying is normally not about single or isolated events but rather about behaviors that are repeated and persistently directed at one or more individuals.

Approximately $5 \%-30 \%$ of the European workforce is found to be exposed to some kind of bullying behavior (Nielsen et al., 2009), and one out of four victims leave their job as a result of such experiences (Rayner, 1997). Consequences of such exposure may be both psychologically and physically debilitating for the targets (Balducci, Alfano, \& Fraccaroli, 2009; Glasø, Nielsen, Einarsen, Haugland, \& Matthiesen, 2009; Hogh, Mikkelsen, \& Hansen, 2011; Rodríguez-Muñoz, Baillien, De Witte, Moreno-Jiménez, \& Pastor, 2009). Bullying may also take its toll on relationships and family life and has been associated with organizational costs such as turnover (Rayner, 1997), absenteeism (Kivimäki, Elovainio, \& Vatera, 2000), and decreased organizational commitment and productivity (Hoel, Einarsen, \& Cooper, 2003). Accordingly, bullying can be costly for the individual, the organization, and the society. However, despite the large body of evidence pointing to such harmful consequences of bullying, little is known about factors pertaining to how and why bullying may produce such outcomes in targets.

From a stress-theoretical point of view (e.g., Lazarus, 1999; Lazarus \& Cohen-Charash, 2001; Lazarus \& Folkman, 1984), emotions may be of great importance to understand the outcomes of stressful transactions such as workplace bullying. In accordance with this idea, emotions are essential to understanding people's reactions at work (Muchinsky, 2000). Research within the field of victimology (e.g., Janoff-Bulman, 1992) has shown that facing harassment at work may be experienced as a trauma and, as such, may generate severe emotional reactions such as fear, anxiety, and shock, as well as lower the target's state of positive feelings. Qualitative studies have shown that emotions such as anxiety, fear, anger, helplessness, and irritability may follow the experience of being bullied (Ayoko, Callan, \& Härtel, 2003). Furthermore, in an Irish interview study, 30 targets of bullying reported high levels of anxiety and depression (O'Moore, Seigne, McGuire, \& Smith, 1998), whereas 
targets at a university in Great Britain reported a high prevalence of shame (Lewis, 2004). Leymann (1990) has also documented high levels of depression, helplessness, anger, anxiety, and despair among bullied targets in psychiatric clinics and such feelings seem to be representative for targets regardless of gender, position, and age (Tracy, Lutgen-Sandvik, \& Alberts, 2006).

Positive emotions also seem to be related to workplace bullying in terms of decreased intensity (see Bowling \& Beehr, 2006; Glasø, Løkke Vie, Holmdal, \& Einarsen, 2011). In line with this view, a study focusing on relationships between stressful events and positive and negative moods experienced by white-collar workers showed that exposure to the stressors intensified their negative emotional experiences while reducing the intensity of their positive mood (van Eck, Nicolson, \& Berkhof, 1998). Recently, Brotheridge and Lee (2010) have demonstrated a significant reduction of happiness among targets of workplace bullying compared to nonvictims. Even though both negative and positive emotions certainly are connected to bullying, most studies mention affective states solely as consequences or end products of bullying (see meta-analysis by Bowling \& Beehr, 2006), thereby leaving out the possible mediating effect emotions may have on the targets' attitude and subsequent behavior.

Nevertheless, a few studies examining affective experiences as possible mediators between workplace bullying and different outcomes do exist. For example, Penhaligon, Louis, and Restubog (2009) tested the mediating role of perceived rejection between workgroup mistreatment and affective outcomes such as depression and organizationbased self-esteem among 142 part-time work participants. The results indicated that perceived rejection mediates the relationship between mistreatment and the outcomes. A study among 224 Danish factory employees found that negative affect partly mediated the relationship between exposure to bullying and self-reported health complaints (Mikkelsen \& Einarsen, 2002). However, the picture is blurred; in a Norwegian study, Matthiesen and Einarsen (2004) did not find any significant mediator or moderator effects of positive or negative emotions between bullying and health problems. Moreover, Glasø et al. (2011), who investigated personality traits and experienced emotions among targets, found that the relationships between exposure to bullying and both job satisfaction and intention to leave were actually partly mediated by the targets' emotional experiences.

These studies indicate that emotional reactions among bullied targets may mediate different outcome variables. As such, the results are mixed and emphasized the need for more studies examining emotional experiences among targets of workplace bullying. Hence, to learn more about mechanisms that may be involved in the development of individual reactions associated with bullying, the present study examines the role of positive and negative emotions as potential mediators between exposure to workplace bullying and outcomes such as organizational commitment, job satisfaction, and intention to leave the organization in a large and heterogeneous sample.

Affective events theory (AET; Weiss \& Cropanzano, 1996) elucidates what happens between work events and subsequent employee attitudes and behaviors by focusing on the role of emotions. AET offers a broad description of the causes, consequences, and structure of affective experiences at work. According to $\mathrm{AET}$, work environment features (i.e., roles and job designs) influence attitudes directly through a cognitive route as well as indirectly through 
an affective route, the latter by determining the occurrence of positive or negative affective work events. Experiencing such "hassles" and "uplifts" at work lead to negative and positive affective reactions, which in turn lead to affect-driven behaviors and work attitudes. Work attitudes may then influence judgment-driven behavior, such as turnover intentions. Weiss and Cropanzano (1996) claim that workplace events activate affective responses, which after being accumulated over time will influence workplace attitudes such as job satisfaction. The model is based on the assumption that emotions are not equal to job satisfaction. More specifically, job satisfaction, rather than constituting an affective phenomenon, is conceptualized as an evaluative judgment of or attitude toward one's job (Spector, 1997). Such an attitude should therefore not be confused with genuine emotions that employees experience at work, because emotions have causes and consequences that are distinguishable from the causes of evaluative judgement such as job satisfaction (Weiss \& Cropanzano, 1996). Hence, in the present study we focus on accumulated emotions by measuring the respondents' positive and negative emotional reactions during the preceding 2 weeks.

Although AET is regarded as a significant contribution toward explaining the causes and consequences of emotions at work, we still need more empirical examination of the basic assumptions put forward in the model (Briner \& Totterdell, 2002; Glas $\varnothing$ et al., 2011; Weiss \& Beal, 2005). The model does not specify the type of work environments or work events that may be associated with positive or negative affective reactions. According to Basch and Fisher (2000), few studies have explored the specific events described in AET that might arouse affect at work. In the present study, a certain kind of negative work event is examined, namely the experience of bullying behaviors at work. Thus, our aim is to investigate whether AET's predictions regarding the fundamental role of emotions can be corroborated by the relationships between bullying and some occupational outcomes, which are described in the following section.

Many studies have shown that exposure to workplace bullying is associated with lowered job satisfaction (Baruch, 2005; Bilgel, Aytac, \& Bayram, 2006; Hauge, Skogstad et al., 2010; Hubert, Furda, \& Steenma, 2001; Quine, 2003), an association that was recently confirmed in a longitudinal study (Rodríguez-Muñoz et al., 2009). In addition, different cross-sectional studies have reported that exposure to workplace bullying is related to low levels of organizational commitment (Hubert et al., 2001; Notelaers \& De Witte, 2003). Several studies have also shown that exposure to bullying is associated with high turnover intention among targets (Baruch, 2005; Hauge et al., 2010; Lutgen- Sandvik, 2006; Rayner, 1997). In their meta-analysis focusing on antecedents and consequences of workplace harassment, Bowling and Beehr (2006) found that environmental and emotional factors were significantly related to the targets' well-being. These find ings fit the predictions suggested in AET, namely that negative events (i e., exposure to bullying) will affect the recipients' work attitudes such as job satisfaction, organizational commitment, or intention to leave the organization. However, none of these studies examined the central premise of AET, namely to what extent individuals' accumulated emotional responses to workplace events mediate the relationship between such events and their cognition and behavior (see Weiss \& Beal, 2005), which is the main focus of the present study. In accordance with AET, we hypothesize the following: Hypothesis 1: Negative emotions mediate the relationships between exposure to bullying and job satisfaction, organizational commitment, and turnover intention, respectively. Specifically, exposure to bullying will be associated with an increase in negative 
emotions, which in turn will be related to a decrease in job satisfaction and organizational commitment and an increased intention to leave the organization, respectively.

Hypothesis 2: Positive emotions mediate the relationships between exposure to bullying and job satisfaction, organizational commitment, and turnover intention, respectively. Specifically, exposure to bullying will be associated with a decrease in positive emotions, which in turn will be related to a decrease in job satisfaction and organizational commitment and an increased intention to leave the organization, respectively.

METHOD Sample Data was collected from a large survey of psychosocial risk factors at work during the period 2003-2007 by means of an anonymous self-report questionnaire and distributed to 12 organizations in Belgium who wanted to conduct a psychosocial risk analysis. Questions about workplace bullying appeared at the very end of the questionnaire. Participation was voluntary, and anonymity was guaranteed by the researchers at the Directorate of the Research of Working Conditions. The organizations operated in the manufacturing industry (25\%), the service sector (44\%), and the public sector (31\%). With respect to size, one organization was small (fewer than 100 employees), three organizations had between 100 and 250 employees, and the remaining eight organizations employed more than 500 people. A total of 5,520 respondents completed the survey, yielding a response rate of $70 \%$, which is well above the mean found in surveys of this kind (see Baruch \& Holtom, 2008). A small majority of the respondents were male, whereas $42 \%$ were female. The mean age of the respondents was 40.5 years (SD 5 10). Approximately $8 \%$ were blue-collar workers, $40 \%$ were white-collar workers, $32 \%$ were public servants, $18 \%$ held managerial positions, and the remaining respondents held social welfare or health care functions (nurses, social workers, medical doctors). Approximately $80 \%$ had a permanent contract and worked full-time. Fifty-three percent of the respondents spoke Dutch, whereas $47 \%$ spoke French. Although this is not a representative sample for the Belgian workforce, it is a heterogeneous sample that allows us to investigate the current mediation hypotheses.

Instruments Exposure to bullying behaviors at work was measured by the short version of the negative acts questionnaire (Einarsen, Hoel, \& Notelaers, 2009; Notelaers \& Einarsen, 2008). This scale presents respondents with nine behavioral items referring to both direct (e.g., verbal abuse, offensive remarks) and indirect (e.g., social isolation, slander) negative acts. All items were described in behavioral terms with no reference to the phrase "bullying," thus, measuring perceived exposure to bullying behaviors without forcing the respondents to label these situations as bullying. For each item, the respondents were asked how often they had been exposed to the specific behavior during the preceding 6 months. The response categories were "never," "now and then," "about monthly," "weekly and more often." In the present study, the scale showed a satisfactory internal consistency measured by Cronbach's alpha $(\mathrm{a}=.82)$.

Emotional experiences were measured by the Questionnaire on the Evaluation and Experience of Work (QEEW; van Veldhoven \& Meijman, 1994). This scale consists of two scales referring to six negative emotions $(a=.84)$ and six positive emotions $(a=.88)$. The respondents were asked to what extent they generally felt the listed emotions during the preceding 2 weeks. The following emotions were listed in the questionnaire: nervous, optimistic, gloomy, at ease, dejected, calm, agitated, sad, relaxed, uncomfortable, cheerful, and elated. Response categories were "not at all," "hardly," "somewhat," and " completely." 
All three outcomes were measured with items included in the QEEW (see also Notelaers, De Witte, van Veldhoven, \& Vermunt, 2007; van Veldhoven \& Meijman, 1994). Job satisfaction was measured with five items. Examples of items are "I do my work because I have to" (reversed), and "Mostly, I am pleased to start on my day's work." Cronbach's alpha = .79. Organizational commitment was measured with five items, and this scale had a reliability of .82. Examples of items are "It is important to me that I can make a contribution to the organization's business," and "I really feel very closely involved with this organization." Turnover intention was measured with four items, such as "I sometimes think about changing my job," and "Next year, I plan to look for a job outside this organization." This scale also showed satisfactory Cronbach's alpha values $(a=.78)$.

Analyses and Statistics According to AET, emotional reactions are considered to mediate the relationships between exposure to workplace bullying and the three outcome variables. To test a mediation model with more than three variables, the traditional Baron and Kenny (1986) approach is less appropriate (MacKinnon, Lockwood, Hoffman, West, \& Sheets, 2002; McQueen, Getz, \& Bray, 2003). Structural equation modeling, however, allows for analyzing several mediators and several outcome variables simultaneously, thereby taking measurement error into account as well. Because the positive and negative emotions were highly correlated in the measurement model, the issues of multicollinearity and suppression recommend modeling of the positive and the negative emotions separately (Maassen \& Bakker, 2001). In the present study, we follow an analytical strategy employed by Geurts, Kompier, Roxburgh, and Houtman (2003) and distinguish between three models to assess mediation.

In the first model, we assume that emotions fully mediate the relation between exposure to bullying and the three outcome variables. In this model, job satisfaction, turnover intention, and organizational commitment are directly explained by emotions. In the second model, we assume that the relation between workplace bullying and the three outcome variables is partially mediated. In this model, job satisfaction, organizational commitment, and turnover intention are explained by emotions and exposure to workplace bullying. If emotions are still contributing to the explained variance of the outcome variables, we can conclude that emotions partially mediate the relationship between workplace bullying and the outcomes. To evaluate the extent of mediation, a third model is estimated. This model differs from the second model because the path coefficients between emotions and three outcome variables are fixed. These parameters are set equal to the estimated parameters of the first model, in which complete mediation was estimated. The difference in $\mathrm{x} 2$ between the second and third model indicates whether emotions mediate the relation between workplace bullying and the three outcome variables. If the difference in $x 2$ between the second and third models is not significant, the model assuming complete mediation is the most appropriate one. If the difference in $\mathrm{x} 2$ between the second and third models is significant, the model in which partial mediation is assumed is the most suitable one. And finally, when the difference in $x 2$ between the second and third models is significant and the relation between emotions and outcome variables is not significant in the second model, the model assuming no mediation is the most suitable one.

These three models are further described based on various commonly reported statistical criteria. We used goodness-of-fit indices; the root mean square error of approximation (RMSEA), the non-normed fit index (NNFI), the comparative fit index (CFI), and the 
standardized root mean square residual (SRMR). RMSEAs and SRMRs that are smaller than .08 are indicative of a satisfactory approximate fit of the theoretical model (Hu \& Bentler, 1999). For the other indices such as the NNFI and the CFI, values greater than .90 (and preferably greater than .95) are considered to indicate a good fit.

RESULTS Table 1 shows some essential descriptive statistics and the Pearson's correlation coefficients for the variables in the study. All correlation coefficients between the variables were significantly different from zero $(p, .001)$. The means in the table show that, on average, the respondents in this sample are modestly exposed to workplace bullying, show somewhat more negative than positive emotions, are very highly satisfied with their current job, are highly committed to the organization, and show a low intention of turnover.

Table 2 contains the fit measures of the LISREL analysis (Jöreskog \& Sörbom, 1993) for the first model (which assumed complete mediation by negative emotions), as well as the fit measures for models where emotions partially mediate the relation between workplace bullying and the outcome variables job satisfaction, organizational commitment, and turnover intention. The first model or basic model (Model 1) in which complete mediation was assumed fitted the data reasonably well. However, with 373 degrees of freedom, the $x 2$ of 6323.47 is too high to obtain a perfect fit. Because the sample size is very large, the $x 2$ is highly inflated. The RMSEA, a measure of approximate fit and other descriptive statistics, is therefore also used. The descriptive statistics showed that this model had a satisfactory fit. In this model, the entire path coefficients between negative emotions and workplace bullying and between negative emotions and outcome variables are significant ( $t$. 1.96). Hence, negative emotions may be conceived as mediators.

Model 2 is the model in which negative emotions partially mediate the relationship between exposure to workplace bullying and the outcome variables. This partial mediation model did lead to a significant improvement of fit $(\mathrm{Dx} 2(3)=36.46)$. The partial mediation model also fitted the data reasonably well. To test the extent of the mediation, we conceptualized Model 3 where the path coefficients between negative emotions and outcome variables were fixed to the estimates in the full mediation model. As shown in Table 2, this model leads to a significant deterioration of fit $(D \times 2(1)=17.58)$. Hence, negative emotions do not fully mediate the relationships between exposure to workplace bullying and job satisfaction, organizational commitment or turnover intentions, respectively. However, because the negative emotions were significant predictors of these three outcome variables in the second model, we may conclude that negative emotions partially mediate the relationships between exposure to workplace bullying and job satisfaction, organizational commitment and turnover intention, respectively. The total amount of explained variance for job satisfaction was $35 \%$, $13 \%$ for turnover intention, and $27 \%$ for organizational commitment.

As shown in Figure 1, workplace bullying was positively related to negative emotions $(b=$ $0.48, p<.001)$. All paths between emotions and the outcome variables were significant. When a simple regression analysis was employed where no mediation was modeled, the direct relationship between workplace bullying and job satisfaction expressed as a standardized path coefficient (b) was 20.43. In the partial mediation model, this coefficient dropped to 20.08. Regarding the relationship between workplace bullying and turnover intention, the beta in the regression model dropped from 0.34 to 0.09 in the final model. Correspondingly, the relationship between workplace bullying and organizational 
commitment revealed a drop from $B=20.41$ to $B=20.11$. Hence, the initial relationships were decimated, indicating that negative emotions may act as substantial mediators between workplace bullying and all three outcomes. This result indicates that our first hypothesis is partly supported.

In examining the potential mediator role of positive emotions, we followed the same procedure and employed the same analyses as for the negative emotions (see previous discussion). Table 3, which contains the fit statistics and the model comparison procedure to evaluate the potential mediation effects, shows that also positive emotions partially mediate the relationships under investigation.

The path coefficients of the partial mediation model are shown in Figure 2. The total amount of explained variance for job satisfaction was $41 \%, 15 \%$ for turnover intention, and $36 \%$ for organizational commitment.

As expected, workplace bullying was negatively related to positive emotions ( $B=20.39, p$, .001). All paths between emotions and the outcome variables were significant. Workplace bullying was still weakly related to turnover intention and to job satisfaction. When a simple regression analysis was estimated where no mediation was modeled, the direct relationship between workplace bullying and job satisfaction expressed as a standardized path coefficient (b) was 20.44. In the partial mediation model, the corresponding path coefficient dropped to 20.11. Whereas the relationship between workplace bullying and turnover intention was 0.34 in the regression model, it dropped to 0.11 in the final model. The relationship between workplace bullying and organizational commitment dropped from 20.42 to 20.11 . Hence, the initial relationships decreased substantially, indicating that positive emotions also act as a substantial mediator between workplace bullying and all three outcomes. This result indicates that our second hypothesis is partly supported.

An essential principle of the AET model is that job satisfaction, organizational commitment, and emotions are related but clearly distinguishable constructs. The results of the present study lend only partial support to this view, because both job satisfaction and positive and negative emotions ( $r 50.64, p, .01 ; r 520.55, p, .01$, respectively) as well as organizational commitment and positive and negative emotions( $r 50.60, p, .01 ; r 520.45, p, .01$, respectively) were strongly correlated. Although AET's contribution to the field seems important, it draws heavily on existing theories of emotion and has not been comprehensively tested (Briner \& Totterdell, 2002). Hence, we wanted to explore this issue further by comparing different factor models. The analyses showed that the fivefactor model distinguishing between the five factors in the current study obtained a better fit (negative emotions, $x 2=5276.83$, df $=367$; positive emotions, $x 2=6053.51$, $d f=367$ ) than other factor models where, for instance, emotions and job satisfaction were conceived as one factor (negative emotions, $x 2=10936.91$, $d f=371$; positive emotions, $x 2=10914.96$, $d f=$ 371 ) or a factor model where emotions, job satisfaction, and organizational commitment were combined into one latent variable (negative emotions, $x 2=13356.02$, $\mathrm{df}=374$; positive emotions, $x 2=13061.33, \mathrm{df}=374$ ) and, finally, where next to workplace bullying only one factor was differentiated (negative emotions $\times 2=15683.33$, df 5367 ; positive emotions $\times 2=$ $15655.46, \mathrm{df}=376$ ). Thus, our findings support the idea of AET that job satisfaction, organizational commitment, and turnover intentions and emotions are distinct empirical and theoretical constructs. 
DISCUSSION The present study indicates that the relationships between exposure to bullying and job satisfaction, organizational commitment, and intention to leave the organization are partly but substantially mediated by the targets' negative and positive emotional experiences. Hence, both our hypotheses are to a certain extent supported.

AET points to affective experiences as being crucial in connection with the outcomes of work events. However, the present findings revealed strong but still only partial mediation. This is in line with several studies demonstrating the detrimental consequences of workplace bullying, and emphasizes the fact that exposure to persistent negative acts at work is felt as a deeply degrading experience with negative effects on both the victim's self, identity, and health (see Glasø et al., 2009; Hogh et al., 2011; Leymann, 1996). A core problem of victimization because of workplace bullying is that such events may threaten or even shatter the target's basic assumptions of being a valuable and competent person living in a safe and caring environment (Janoff-Bulman, 1992). Accordingly, it seems reasonable that the targets in the present study speak of strong negative emotional reactions as well as reduced levels of positive emotions.

To explain the mediating effects of emotional reactions in this study, it may be fruitful to think of negative emotions as states producing a more critical attitude within individuals than do positive emotions (e.g., George, 2000). Hence, it seems sensible, and in accordance with $\mathrm{AET}$, that the targets in the present study will-after having repeatedly experienced negative emotions during the preceding 2 weeks-become increasingly more attentive, doubtful of or skeptical toward their work environment, and that their emotional reactions as such may influence their attitudes regarding their job satisfaction, organizational commitment, and intention to leave the organization.

Nevertheless, positive emotions measured in the present study such as optimism, cheerfulness, and calmness also mediated the relationship between bullying and the outcomes. Hence, bullying not only generates negative emotions, but it also seems to reduce the positive ones, and in effect reduces job satisfaction and organizational commitment while increasing the targets' intentions to seek employment elsewhere. This result seems to support our second hypothesis as well as predictions of AET. However, this result is not in accordance with another central theory of emotions, namely the two-domain theory of emotions (TDT; Fisher, 2002), which claims that an individual's emotional system consists of two separate parts, positive and negative affects, which are activated by different stimuli. Consistent with TDT, it could be reasoned that bullying is not likely to be related to the presence or absence of positive affect in targets because positive emotions are likely to be predicted by events other than bullying. On the other hand, appraisal theories of emotion (Lazarus, 1999; Roseman, 1991) claim that an individual's appraisal of the situation determines his or her subsequently affective response. Being exposed to workplace bullying may undermine the target's self confidence and, as shown in the present study, lead to a reduction of positive emotions within the target (see also Brotheridge \& Lee, 2010).

Furthermore, positive emotions may have significant behavioral implications concerning the targets' coping efforts. For instance, Tugade, Fredrickson, and Barrett (2004) have shown that positive emotions play a crucial role in enhancing coping resources in the face of negative events. As shown in the present study, exposure to workplace bullying seems to 
decrease the intensity of the targets' positive emotions and may accordingly have weakened their coping resources. In this respect, their emotional reactions may have influenced their coping capacity and, subsequently, their choice of coping strategy. If so, one such coping strategy may be the targets' intentions to leave the organization because this act removes them from the source of the problem and accordingly reduces the emotional pain. Some other targets may quit in despair or because of sickness resulting from prolonged strain and stress.

The mediating effect of emotions on the targets' levels of job satisfaction, organizational commitment, and intention to leave may have serious negative organizational effects. Although research on organizational commitment among targets of workplace bullying is scarce, it is reasonable to expect a negative impact on productivity and performance where reduced commitment or withdrawal is used as a coping strategy (see also Hoel, Sheehan, Cooper, \& Einarsen, 2011, for a similar view). In contrast, several studies have shown that employees with a strong organizational commitment are loyal to the organization and exhibit extra efforts at work (Meyer, Stanley, Herscovitch, \& Toplonytsky, 2002), are highly motivated (Kacmar, Carlson, \& Brymer, 1999), and showing less need to change their jobs (Jaros, 1997) than employees with a weak organizational commitment. In a British study, targets of bullying rated their own performance to be around $85 \%$ of normal capacity, whereas people with no bullying experiences reported $92 \%$ capacity (Hoel, Cooper, \& Faragher, 2001). Moreover, the mediating effects of decreased levels of experienced positive emotions and increased levels of negative emotions shown in the present study may also influence the targets' level of job engagement, creativity, and innovation (see Isen, 2000; Isen, Daubman, \& Nowicki, 1987; Rayner, Hoel, \& Cooper, 2002), which should be studied in more details in future studies.

In a study on bullying and absenteeism in the United Kingdom, Hoel and Cooper (2000) found that victims of bullying took on average 7 days more sick leave per year than those who were neither bullied nor had witnessed that bullying had taken place. Based on a prevalence rate of bullying of $10 \%$, this would account for a total of 18 million lost working days annually in the United Kingdom alone. Based on a meta-analysis of bullying research, Sheehan, McCarthy, Barker, and Henderson (2001) calculated a bullying cost in the order of AU\$ 0.6-3.6 million per annum for an Australian business with 1,000 employees. Similarly, at a national level, Hoel et al. (2003) concluded that costs related to absence and replacement because of bullying alone may account for close to £2 billion annually. However, one should bear in mind that intention to leave the organization as a research variable used in the present study is considered only to measure an individual's attitude toward the job, as O'Connell, Calvert and Watson (2007) reported that $60 \%$ of some Irish targets considered leaving, whereas $15 \%$ actually leftthe organization. Nevertheless, bullying represents a considerable cost both to employees, employers, and the society (Di Martino, Hoel, \& Cooper, 2003), and the results of the present study indicate that experienced emotions seem to play a central role in this process. Of course, a cognitive route may also partially account for these relationships and should be investigated in further studies.

Finally, a crucial principle of the AET model is that emotion, job satisfaction, organizational commitment, and turnover intention are related but nevertheless dissimilar constructs. Our findings, however, only partially give support to this view, because these variables were strongly correlated. We therefore explored this issue further by comparing different factor 
models (see "Results" section). The analyses showed that the five-factor model distinguishing between the five constructs examined in the present study obtained a better fit than other factor models. Thus, our findings support the idea of AET, namely that emotion, job satisfaction, organizational commitment, and turnover intention are distinct empirical and theoretical constructs and should therefore be explicated and studied as such (see also Ashkanasy, Zerbe, \& Härtel, 2002, for a similar view). In this respect, we believe that the use of general job satisfaction or general organizational commitment measures as the only indicators of affective experiences at work has limited value.

METHODOLOGICAL ISSUES One important limitation of the present study stems from the use of single-source selfreported data. Although exposure of bullying, emotional experiences, job satisfaction, organizational commitment, and intentions to leave must be measured by self-reports, common method variance may have enhanced the overall strength of correlations (see Podsakoff, MacKenzie, Lee, \& Podsakoff, 2003). By measuring emotions, we chose emotional reactions from the QEEW because of its good psychometric qualities and the fact that this instrument is extensively used in the European Lowlands. However, because of multicollinearity $(r$. 0.65) and possible suppression effects, the different kinds of positive and negative emotions could not be investigated simultaneously. Therefore, future studies may use the Positive and Negative Affect Schedule (PANAS), which comprises two distinct dimensions (positive affect/negative affect), which is a psychometrically sound and widely used instrument in the field (see Watson, Clark, \& Tellegen, 1988; Weiss \& Cropanzano, 1996). Asking respondents to which extent they experience positive and negative emotions with a time frame of 2 weeks seems quite suitable considering the fact that AET emphasizes the point of measuring accumulated emotions in explaining the outcome variables examined in the present study. Furthermore, when bullying becomes more or less an enduring state, it may both act as a daily hassle and constitute a more permanent feature of the working environment. Following AET, bullying should then have both direct and indirect effects on the outcomes, in line with the findings of the present study.

However, one should keep in mind that because of the cross-sectional design of the present study, we cannot conclude about the causal relationship between the variables. This may imply that reduced job satisfaction and reduced organizational commitment as well as plans to quit one's job contribute to those emotional reactions reported in this study. Furthermore, such withdrawal may be understood from the perspective of ostracism (see Williams, 1997), which might explain the expelling process of the targets from the workplace. Only a longitudinal study would provide valid data about causality of the impact of emotions on the variables in question. It should also be noted that measuring emotions is complicated, because emotional experiences are variable and transient (see e.g., Ben-Ze'ev, 2000) and may be difficult to recall and report accurately long after they have occurred (Fisher, 2002). However, in this study we focused on accumulated emotions, which, according to AET, are central to explaining behavioral and attitudinal outcomes at work. Nevertheless, we think future research also should examine such relationships longitudinally on an hourly or daily basis.

CONCLUSION The present study has documented, in accordance with AET, that both negative and positive emotions partly mediate the relationships between exposure to bullying and outcomes such as job satisfaction, organizational commitment, and intention to leave the 
organization. Hence, the consequences of workplace bullying are severe, and the targets' experienced emotions seem to be strongly connected to this problem.

REFERENCES Ashkanasy, N. M., Zerbe, W. J., \& Härtel, C. E. J. (2002). Managing emotions in the workplace. New York: M. E. Sharpe.

Ayoko, O. B., Callan, V. J., \& Härtel, C. E., J. (2003). Workplace conflict, bullying, and counterproductive behaviours. The International Journal of Organizational Analysis, 11(4), 283-301.

Balducci, C., Alfano V., \& Fraccaroli, F. (2009). Relationships between mobbing at work and MMPI-2 personality profile, posttraumatic stress symptoms, and suicidal ideation and behavior. Violence and Victims, 24(1), 52-67.

Baron, R. M., \& Kenny, D. A. (1986). The moderator-mediator variable distinction in social psychological research: Conceptual, strategic, and statistical considerations. Journal of Personality and Social Psychology, 51(6), 1173-1182.

Baruch, Y. (2005). Bullying on the net: Adverse behavior on e-mail and its impact. Information \& Management, 42, 361-371.

Baruch, Y., \& Holtom, B. C. (2008). Survey response rate levels and trends in organizational research. Human Relations, 61(8), 1139-1160.

Basch, J., \& Fisher, C. D. (2000). Affective events-emotion matrix: A classification of work events and associated emotions. In N. M. Ashkanasy, C. E. J. Härtel, \& W. J. Zerbe (Eds.), Emotions in the workplace: Research, theory and practice (pp. 36-48). Westport, CT: Quorum Books.

Ben-Ze'ev, A. (2000). The subtlety of emotions. Cambridge, MA: MIT Press.

Bilgel, N., Aytac, S., \& Bayram, N. (2006). Bullying in Turkish white-collar workers. Occupational Medicine, 56(4), 226-231.

Bowling, N. A., \& Beehr, T. A. (2006). Workplace harassment from the victim's perspective: A theoretical model and meta-analysis. The Journal of Applied Psychology, 91(5), 998-1012.

Briner, R. B., \& Totterdell, P. (2002). The experience, expression and management of emotion at work. In P. Warr (Ed.), Psychology at work (5th ed., pp. 229-252). London: Penguin Books.

Brotheridge, C. M., \& Lee, R. T. (2010). Restless and confused. Emotional responses to workplace bullying in men and women. Career Development International, 15(7), 687-707.

Di Martino, V., Hoel, H., \& Cooper, C. L. (2003). Preventing violence and harassment in the workplace. Luxembourg: Office for Official Publications of the European Communities.

Einarsen, S., \& Hoel, H. (2008). Bullying and mistreatment at work: How managers may 
prevent and manage such problems. In A. Kinder, R. Hughes, \& C. L. Cooper (Eds.), Employee well-being support: A workplace resource (pp. 161-173). New York: Wiley.

Einarsen, S., Hoel, H., \& Notelaers, G. (2009). Measuring exposure to bullying and harassment at work: Validity, factor structure and psychometric properties of the Negative Acts Questionnaire- Revised. Work \& Stress, 23(1), 24-44.

Fisher, C. D. (2002). Antecedents and consequences of real-time affective reactions at work. Motivation and Emotion, 26(1), 3-30.

George, J. M. (2000). Emotions and leadership: The role of emotional intelligence. Human Relations, 53(8), 1027-1055.

Geurts, S. A. E., Kompier, M. A. J., Roxburgh, S., \& Houtman, I. L. D. (2003). Does workhome interference mediate the relationship between workload and well-being? Evaluating model fit. In R. H. Hoyle (Ed.), Structural equation modelling: Concepts, issues and applications (pp. 76-99). Thousand Oaks, CA: Sage.

Glasø, L., Løkke Vie, T., Holmdal, G., \& Einarsen, S. (2011). An application of affective events theory to workplace bullying: The role of emotions, trait anxiety and trait anger. European Psychologist, 16, advance articles.

Glasø, L., Nielsen, M., Einarsen, S., Haugland, K., \& Matthiesen, S. (2009). A study of basic life assumptions and post-traumatic stress disorder among victims of workplace bullying. Journal of the Norwegian Psychological Association, 46, 153-160.

Hauge, L. J., Skogstad A., et al. (2010). The relative impact of workplace bullying as a social stressor at work. Scandinavian Journal of Psychology, Early online.

Hoel, H., \& Cooper, C. L. (2000). Destructive conflict and bullying at work: Report. Manchester, United Kingdom: Manchester School of Management.

Hoel, H., Cooper, C., L., \& Faragher, B. (2001). The experience of bullying in Great Britain: The impact of organizational status. European Journal of Work and Organizational Psychology, 10(4), 443-465.

Hoel, H., Einarsen, S., \& Cooper, C. L. (2003). Organisational effects of bullying. In S. Einarsen, H. Hoel, D. Zapf, \& C. L. Cooper (Eds.), Bullying and emotional abuse in the workplace: International perspectives in research and practice (pp. 145-162). London: Taylor \& Francis.

Hoel, H., Sheehan, M., Cooper, C. L., \& Einarsen, S. (2011). Organisational effects of workplace bullying. In S. Einarsen, H. Hoel, D. Zapf, \& C. L. Cooper (Eds.), Bullying and harassment in the workplace: Developments in theory, research, and practice (pp.129-148). Boca Raton, FL: CRC Press.

Hogh, A., Mikkelsen, E. G., \& Hansen, Å. M. (2011). Individual consequences of workplace bullying/mobbing. In S. Einarsen, H. Hoel, D. Zapf, \& C. L. Cooper (Eds.), Bullying and 
harassment in the workplace: Developments in theory, research, and practice (pp. 107-128). Boca Raton, FL: CRC Press.

Hu, L., \& Bentler, P. M. (1999). Cutoffcriteria for fit indices in covariance structure analysis: Conventional criteria versus new alternatives. Structural Equation Modeling: A Multidisciplinary Journal, 6(1), 1-55.

Hubert, A., Furda, J., \& Steenma, H. (2001). Mobbing, systematisch pestgedrag in organisaties. Gedrag en Organisatie, 14(6), 378-395.

Isen, A. M. (2000). Positive affect and decision making. In M. Lewis \& J. M. Haviland-Jones (Eds.), Handbook of emotions (2nd ed., pp. 417-435). New York: Guilford Press.

Isen, A. M., Daubman, K. A., \& Nowicki, G. P. (1987). Positive affect facilitates creative problem solving. Journal of Personality and Social Psychology, 52(6), 1122-1131.

Janoff-Bulman, R. (1992). Shattered assumptions: Towards a new psychology of trauma. New York: Free Press.

Jaros, S. J. (1997). An assessment of Meyer and Allen's (1991) three-component model of organizational commitment and turnover intentions. Journal of Vocational Behavior, 51(3), 319-337.

Jöreskog, K. G., \& Sörbom, D. (1993). LISREL 8: Structural equation modeling with the SIMPLIS command language. Chicago: Scientific Software International.

Kacmar, K. M., Carlson, D. S., \& Brymer, R. A. (1999). Antecedents and consequences of organizational commitment: A comparison of two scales. Educational and Psychological Measurement, 59(6), 976-994.

Kivimäki, M., Elovainio, M., \& Vatera, J. (2000). Workplace bullying and sickness absence in hosptial staff. Occupational and Environmental Medicine, 57(10), 656-660.

Lazarus, R. S. (1999). Stress and emotion: A new synthesis. New York: Springer Publishing.

Lazarus, R., \& Cohen-Charash, Y. (2001). Discrete emotions in organizational life. In R. L. Payne \& C. L. Cooper (Eds.), Emotions at work: Theory, research and applications for management (pp. 45-81). Chichester, United Kingdom: Wiley.

Lazarus, R. S., \& Folkman, S. (1984). Stress, appraisal and coping. New York: Springer Publishing.

Lewis, D. (2004). Bullying at work: The impact of shame among university and college lecturers. British Journal of Guidance and Counselling, 32(3), 281-299.

Leymann, H. (1990). Mobbing and psychological terror at workplaces. Violence and Victims, 5(2), 119-126. 
Leymann, H. (1996). The content and development of mobbing at work. European Journal of Work and Organizational Psychology, 5(2), 165-184.

Lutgen-Sandvik, P. (2006). Take this job and . . : Quitting and other forms of resistance to workplace bullying. Communication Monographs, 73(4), 406-433.

Maassen, G., \& Bakker, A. (2001). Suppressor variables in path models: Definitions and interpretations. Sociological Methods \& Research, 30(2), 241-270.

MacKinnon, D. P., Lockwood, C. M., Hoffman, J. M., West, S. G., \& Sheets, V. (2002). A comparison of methods to test mediation and other intervening variable effects.

Psychological Methods, 7(1), 83-104.

Matthiesen, S. B., \& Einarsen, S. (2004). Psychiatric distress and symptoms of PTSD among victims of bullying at work. British Journal of Guidance \& Counselling, 32(3), 335-356.

McQueen, A., Getz, J. G., \& Bray, J. H. (2003). Acculturation, substance use, and deviant behavior: Examining separation and family conflict as mediators. Child Development, 74(6), 1737-1750.

Meyer, J. P., Stanley, D. J., Herscovitch, L., \& Topolnytsky, L. (2002). Affective, continuance, and normative commitment to the organization: A meta-analysis of the antecedents, correlates, and consequences. Journal of Vocational Behavior, 61(1), 20-52.

Mikkelsen, E. G., \& Einarsen, S. (2002). Bullying in Danish work-life: Prevalence and health correlates. European Journal of Work and Organizational Psychology, 10, 393-413.

Muchinsky, P. M. (2000). Emotions in the workplace: The neglect of organizational behaviour. Journal of Organizational Behavior, 21, 801-805.

Nielsen, M. B., Skogstad, A., Matthiesen, S. B., Glasø, L., Aasland, M. S., Notelaers, G., et al. (2009). Prevalence of workplace bullying in Norway: Comparisons across time and estimation methods. European Journal of Work and Organizational Psychology, 18(1), 81101.

Notelaers, G., \& De Witte, H. (2003). De relatie tussen werkstress en pesten op het werk en welbevinden op het werk [The relationship between workstressors, workplace bullying and wellbeing]. Arbeidsmarktonderzoekersdag, 2003 Vrij Universiteit Brussel. W. Herremans. Reeks, De Arbeidsmarkt in Vlaanderen. Leuven, Steunpunt Werkgelegenheid, Arbeid en Vorming 26 mei 2003, VUB.: 139-163.

Notelaers, G., De Witte, H., van Veldhoven, M., \& Vermunt, J. K. (2007). Construction and validation of the short inventory to monitor psychosocial hazards. Médecine du Travail \& Ergonomie, 44, 11-17.

Notelaers, G., \& Einarsen, S. (2008). The construction and validity of the Short-Negative Acts Questionnaire. Paper presented at the 6th International Conference on Workplace Bullying: Sharing our Knowledge, Montreal, Canada. 
O'Connell, P. J., Calvert, E., \& Watson, D. (2007). Bullying in the workplace: Survey report. Dublin, Ireland: Department of Enterprise Trade and Employment, Economic and Social Research Institute.

O'Moore, M., Seigne, E., McGuire, L., \& Smith, M. (1998).Victims of workplace bullying in Ireland. The Irish Journal of Psychology, 19(2-3), 345-357.

Penhaligon, N. L., Louis, W. R., \& Restubog, S. L. D. (2009). Emotional anguish at work; The mediating role of perceived rejection on workgroup mistreatment and affective outcomes. Journal of Occupational Health Psychology, 14(1), 34-45.

Podsakoff, P. M., MacKenzie, S. B., Lee, J. Y., \& Podsakoff, N. (2003). Common method biases in behavioral research: A critical review of the literature and recommended remedies. Journal of Applied Psychology, 88(5), 879-903.

Quine, L. (2003). Workplace bullying, psychological distress, and job satisfaction in junior doctors. Cambridge Quarterly of Healthcare Ethics, 12(1), 91-101.

Rayner, C. (1997). The incidence of workplace bullying. Journal of Community \& Applied Social Psychology, 7, 199-208.

Rayner, C., Hoel, H., \& Cooper, C. L. (2002). Workplace bullying: What we know, who is to blame, and what can we do? London: Taylor \& Francis.

Rodríguez-Muñoz, A., Baillien, E., De Witte, H., Moreno-Jiménez, B., \& Pastor, J. C. (2009). Cross-lagged relationships between workplace bullying, job satisfaction and engagement: Two longitudinal studies. Work and Stress, 23(3), 225-243.

Roseman, I. J. (1991). Appraisal determinants of discrete emotions. Cognition and Emotion, 5(3), 161-200.

Sheehan, M., McCarthy, P. Barker, M., \& Henderson, M. (2001, June-July). A model for assessing the impact and costs of workplace bullying. Paper presented at the Standing Conference on Organizational Symbolism (SCOS), Trinity College, Dublin, Ireland.

Spector, P. E. (1997). Job satisfaction: Application, assessment, cause, and consequences. London: Sage.

Tracy, S. J., Lutgen-Sandvik, P., \& Alberts, J. K. (2006). Nightmares, demons and slaves: Exploring the painful metaphors of workplace bullying. Management Communication Quarterly, 20, 148-185.

Tugade, M. M., Fredrickson, B. L., \& Barrett, L. F. (2004). Psychological resilience and positive emotional granularity: Examining the benefits of positive emotions on emotion regulation and health. Journal of Personality, 72(6), 1161-1190.

Van Eck, M., Nicolson, N. A., \& Berkhof, J. (1998). Effects of stressful daily events on mood 
states: Relationship to global perceived stress. Journal of Personality and Social Psychology, 75(6), 1572-1585.

Van Veldhoven, M., \& Meijman, T. F. (1994). Het meten van psychosocialea rbeidsbelasting met een vragenlijst: de vragenlijst beleving en beoordeling van de arbeid (VBBA) [The measurement of psychosocial job demands with a questionnaire: The questionnaire on the experience and evaluation of work (QEEW)]. Amsterdam: Nederlands Instituut voor Arbeidsomstandigheden.

Watson, D., Clark, L. A., \& Tellegen, A. (1988). Development and validation of brief measures of positive and negative affect: The PANAS scales. Journal of Personality and Social Psychology, 54(6), 1063-1070.

Weiss, H. M., \& Beal, D. J. (2005). Reflections on affective events theory. In N. M. Ashkanasy, W. J. Zerbe, \& C. E. J. Härtel (Eds.), Research on emotion in organization: The effect of affect in organizational settings (pp. 1-22). Oxford, United Kingdom: Elsevier/JAI.

Weiss, H. M., \& Cropanzano, R. (1996). Affective events theory: A theoretical discussion of the structure, causes, and consequences of affective experiences at work. Research in Organizational Behavior, 18, 1-74.

Williams, K. D. (1997). Social ostracism. In R. M. Kowalski (Ed.), Aversive interpersonal behaviors (pp. 133-170). New York: Plenum Press.

Lars Glasø, PhD BI Norwegian Business School, Oslo, Norway University of Bergen, Norway Guy Notelaers, PhD School of Business and Economics, Department of Organization and Strategy, Maastricht University, The Netherlands University of Bergen, Norway

Correspondence regarding this article should be directed to Lars Glas $\varnothing, \mathrm{PhD}, \mathrm{BI}$ Norwegian Business School, Nydalsveien 37, 0484 Oslo, Norway. E-mail: Lars.Glaso@bi.no (c) 2012 Springer Publishing Company 